\title{
Conditioned inhibition of analgesia
}

\author{
ERIC P. WIERTELAK, LINDA R. WATKINS, and STEVEN F. MAIER \\ University of Colorado, Boulder, Colorado
}

\begin{abstract}
Stimuli that predict the occurrence of aversive events come to elicit conditioned analgesia. Experiments $1 \mathrm{~A}$ and $1 \mathrm{~B}$ examined the possibility that conditioning can inhibit analgesia when stimuli are paired in a backward fashion with a shock US (Pavlovian CS-s). Analgesia conditioned in response to shock context exposure was reversed during the CS-(light) presentation after four sessions. The ability of the CS- to function as a conditioned inhibitor of analgesia was then evaluated in both summation (Experiment 1A) and retardation-of-acquisition testing (Experiments 1A and 1B). The results support the conclusion that a stimulus presented after shock in a backward fashion comes to be a conditioned inhibitor of analgesia. Experiments $2 \mathrm{~A}$ and $2 \mathrm{~B}$ examined the assumption that the results obtained with our pain sensitivity measure (tailflicking in response to radiant heat) reflect changes in responsiveness to painful input, rather than a general motor inhibition or general insensitivity to sensory input. In Experiment 2A, tailflick responding to painful and nonpainful input was compared in animals receiving either morphine or saline. In Experiment 2B, tailflick responding to painful and nonpainful input to the tail was compared in both the shock and a neutral context. In both experiments, only the painful input yielded changes in responsivity. The results support the conclusion that the alterations in pain sensitivity produced by the CS- for shock represents a conditioned inhibition specific to pain.
\end{abstract}

The brain contains neural circuits that descend to the spinal cord, where they are able to activate neurons that inhibit the ascending transmission of nociceptive information, thereby resulting in the inhibition of pain (Basbaum \& Fields, 1984). The existence of these endogenous pain inhibition mechanisms has led to a search for their environmental triggers. This research has revolved around noxious or aversive stimulation. Such stimulation can indeed produce a powerful analgesic reaction, as can both innate and learned danger signals or previously neutral stimuli (Pavlovian CSs) that have been associatively paired with an aversive event (Fanselow, 1986). Moreover, both inherently aversive and conditioned aversive stimuli (Pavlovian CSs that have been paired with shock) produce analgesia by activating the descending neural circuits referred to above (Watkins, Cobelli, \& Mayer, 1982; Watkins, Kinscheck, \& Mayer, 1984). The fact that this machinery is activated by noxious events and signals for noxious events has suggested several functions that might be served by these endogenous pain inhibition systems (Fanselow, 1986; Grau, 1987; Maier, 1989).

A common assumption is that decreased pain sensitivity/ reactivity serves to facilitate efficient defensive behavior during threat. These same considerations would suggest that it would be adaptive for analgesia to be terminated

Preparation of this article was supported in part by NSF Grant BN 8809527 and NIMH Training Grant 5T32MH14617-15 to S.M. We gratefully acknowledge Laura Subel and Kelli Mooney-Heiberger's help in collecting data, as well as the assistance of the members of the Maier and Watkins laboratories, especially Ken Short, for comments on an earlier draft. Correspondence should be addressed to E. P. Wiertelak, Department of Psychology, University of Colorado, Boulder, CO 80309. at the conclusion of threat. Just as signals for danger elicit analgesia, signals for safety might be expected to inhibit analgesia.

The purpose of the reported experiments was to determine whether signals for safety (Pavlovian CS-s) indeed come to serve as conditioned inhibitors of analgesia. In Experiment 1A, we examined the possibility that neutral stimuli can come to inhibit analgesia when they are presented immediately following an analgesia-producing electric shock US. A group of rats received backward-paired presentations of a shock US and a visual (constant light) CS-. Backward presentations of a US followed by a CS have often been used to establish conditioned inhibition (see, e.g., Moscovitch \& LoLordo, 1968; Williams \& Overmier, 1988). The ability of the CS- to function as a conditioned inhibitor of analgesia was evaluated by comparing the performance of animals that had received the backward-paired presentations with that of a control group that received uncorrelated presentations of the CS and US. This comparison was accomplished in tests analogous to those typically used to assess the existence of Pavlovian conditioned inhibition. These are summation testing (see, e.g., Pavlov, 1927) and retardation-of-acquisition testing (Rescorla, 1969). In summation testing, the impact of the cue on the responding produced by a CS + (here the shock context) is measured. If a stimulus is inhibitory, it will reduce the responding (here analgesia) produced by the $\mathrm{CS}+$. In retardation-of-acquisition testing, the CS- is paired with the US (here shock) in a forward direction. If the CS- is inhibitory, excitatory conditioning should be slow.

Pain sensitivity was measured on the tailflick test (D'Amour \& Smith, 1941), a widely accepted measure of 
radiant heat pain threshold. The tailflick test is extensively used in pain research, since a nearly perfect correlation has been found between the ability of a test drug to elevate the rat tailflick latency and the ability of the test drug to suppress human reports of pain (Grumbach, 1966). Because the tailflick itself is a spinally mediated reflex, changes in tailflick latencies on the tailflick test can be used to assess the extent to which mechanisms in higher structures exert descending control over pain sensitivity.

\section{EXPERIMENT 1A}

\section{Method}

\section{Subjects}

The subjects were 16 experimentally naive male Sprague-Dawley rats (Holtzman; Madison, Wisconsin), 100-110 days old at the start of experimentation. All animals were maintained on a 12:12-h light:dark cycle and group housed with food and water continuously available. Experimentation occurred during the light phase of the cycle, between 1200 and $1900 \mathrm{~h}$. Care and use of the animals in all described procedures were in accordance with protocols approved by the University of Colorado laboratory animal research committee.

\section{Apparatus}

Inescapable shocks were administered while the rats were loosely restrained in Plexiglas tubes $17.5 \mathrm{~cm}$ in length and $7.0 \mathrm{~cm}$ in diameter. Each animal's tail extended through a hole in the rear of its particular tube, allowing for either the delivery of tailshock or tailflick testing without removal of the animal from the tube. The restraint tubes rested on individual platforms at a height that allowed testing without moving the animals. Each platform was positioned facing the open door of a sound- and light-attenuating chamber. These chambers were equipped with ventilation fans, which provided background noise, and with a positionable 28-V lamp (General Electric No. 1821), the illumination of which served as the discrete CS. The experimental chambers were contained within an $8 \times 8 \mathrm{ft}$. room that also contained the microcomputer used for the control of all experimental apparatuses except that used for the tailflick testing. The room was dimly illuminated and maintained at a constant $27^{\circ} \mathrm{C}$. Unscrambled 1.0-mA shocks were delivered by shock sources modeled after the Grason-Stadler Model 700 shock source through fuse clip electrodes taped to the rat's tail and augmented by electrode paste.

Pain responsivity was measured using a modification (Akil \& Mayer, 1972) of the tailflick test. The tailflick apparatus consisted of a metal box $13.5 \mathrm{~cm}$ long $\times 7 \mathrm{~cm}$ wide $\times 6.5 \mathrm{~cm}$ high on which the animal's tail rested. Light from a projector lamp (General Electric BMY, $100 \mathrm{~W}, 120 \mathrm{~V}$ ) was focused by a concave reflecting mirror through a hole in the top of the box in order to heat a 5-mmdiameter area on the ventral surface of the tail. The same switch that allowed timing of tailflick latencies (defined as the time from onset of the light until the rat flicked its tail away from the heat stimulus) also controlled the power to the lamp. The lamp's intensity was adjusted by a variable ac transformer so that baseline latencies were 3-4 sec. In the event that no tailflick occurred, the lamp was automatically turned off after $10.0 \mathrm{sec}$ to prevent tissue damage.

\section{Procedure}

Days 1 -5: Restrainer training. The subjects first received 5 daily restrainer training sessions in order to habituate them to both the restraint tubes and handling. The animals were placed in the restrainer tubes for each session while in the animal colony room, and then they were taken to the experimentation room. The animals (in restrainer tubes) were placed on the platforms set into the door openings of the sound-attenuating chambers. Electrode paste was applied to the fuse clip electrodes, and the electrodes were attached and taped to the distal third of each animal's tail. The electrodes remained attached for the duration of each session and were not removed for tailflick testing. The $28-\mathrm{V}$ lamp (unlit) was positioned 4-5 cm in front of the restrainer at the animal's eye level. Beginning $10 \mathrm{~min}$ later, all animals were given a series of 5 tailflick test trials spaced 2 min apart. The animals then remained on the platforms in the chambers for a total session time each day of $25 \mathrm{~min}$, at which time they were returned to the animal colony. Neither shock nor light was presented during these sessions.

Days 6-9: Conditioning. On the day following the final restrainer training session, the animals were randomly assigned to either the backward ( $n=8)$ or the control $(n=8)$ group. Beginning that day, all animals in the backward group received daily backward US-CS pairing sessions. All animals in the control (uncorrelated control) group received daily uncorrelated CS and US presentations. US presentations and tailflick testing occurred at the same times for all animals in both groups. Only the CS- presentation times were varied between groups. The daily conditioning sessions were conducted at approximately the same time each day.

The animals were placed in the restrainer tubes, transported, and then prepared for each conditioning session as in restrainer training sessions. At 10 min into the session, all animals received a series of four experimental-context tailflick test trials spaced 2 min apart. For animals in the backward group, this was followed 2 min later by the first of three US-CS pairings. The US consisted of a 25-sec, 1-mA shock (this intensity of shock was observed to produce maximal analgesia in an earlier pilot study). The CS consisted of a $75-\mathrm{sec}$ illumination of the $28-\mathrm{V}$ lamp (minimum duration allowing tailflick test trials to be completed during the stimulus presentation). Subsequent US-CS presentations were separated by variable 20 -sec (range: $10-30 \mathrm{sec}$ ) intervals. The variable interval was employed as a control for the possibility that animals might rely on temporal cues rather than on the discrete CS for conditioning. For animals in the Control group, all US presentations occurred at the same times as they did for the backward group, but the three CS-presentations were varied so that CS1 occurred at some point within the initial $10 \mathrm{~min}$ of the session, CS2 occurred between subsequent US presentations, and CS3 occurred after all US presentations had been completed for the session.

Although tailflick testing produced only a minor disturbance of the subjects, any disruption at all during the conditioning series seemed undesirable. Thus tailflicking during the CS- was assessed only during the last of the three CS- presentations each day, beginning immediately after onset of the CS-presentation. This procedure permitted the possibility that any inhibition of analgesia observed during the $\mathrm{CS}-$, relative to the analgesia measured during the context, could be produced by temporal cues deriving from the completion of the three daily shocks. That is, any reduction in analgesia might have occurred because the last of the three daily shocks had just occurred, rather than because the CS- was present. Thus, a test tailflick was taken for the control animals at the identical point in time, soon after the third US of the day. There was no CS present at this time. A tailflick during the third CS of the day was not taken for the controls. This is because the CS was farther removed from shock for the controls than for the backward subjects and would therefore not be comparable. Tailflicking during the CS was measured for both groups later in the experiment (see below). The animals remained in the chambers for a total session time of 25 min each day. Daily conditioning sessions were continued for 4 days, at which time backward group tailflick latencies in the presence of the CS- did not differ from those measured after restrainer training.

Day 10: Summation test. On the day after the final conditioning session, all animals in both groups received a summation test. The rats were placed in the restrainer tubes as before. Ten minutes later, the animals in both groups received four tailflick test trials spaced 2 min apart while in the colony room, to establish non- 
experimental context baseline tailflick latencies. These tailflick tests were necessary to demonstrate that the experimental context was a CS+ for analgesia. This established an excitatory baseline from which to test the putative conditioned inhibitor ( $\mathrm{CS}-$ ). The animals were then taken to the experimentation room and prepared as above. At $10 \mathrm{~min}$ into the session, all animals received four tailflick test trials spaced 2 min apart. Two minutes later, a single presentation of the $75-\mathrm{sec} \mathrm{CS}-$ (the $28-\mathrm{V}$ lamp illumination) without presentation of the US was given. All animals received one tailflick test trial during the CS - presentation to measure the summation of the $\mathrm{CS}+$ (experimental context) and the CS- (light). The animals remained in the chambers for a total session time of approximately $25 \mathrm{~min}$.

Days 11-14: Extinction of excitatory contextual CS + . To perform the retardation-of-acquisition test, it was first necessary to extinguish the contextual CS + . All animals in both groups received the first of daily extinction trials, beginning on the day after the summation test session. Neither shock nor light was presented during these sessions. The animals were prepared for the session in the same way as above; then they received the first of a series of tailflick test trials. Subsequent tailflick test trials occurred at 2, 4, 6, $8,10,15$, and every $5 \mathrm{~min}$ after, until all tailflick latencies had returned to the 3-4 sec baseline. Daily extinction sessions were continued until latencies in the presence of the CS+ for all animals in each group did not differ from latencies measured after restrainer training (four sessions).

Days 15-27: Retardation-of-acquisition test. On the day following the final contextual CS+ extinction session, all animals received the first of what would be alternating daily reinforced and nonreinforced sessions (i.e., sessions in which neither the CS nor the US was presented; these were procedurally the same as restrainer training) at approximately the same time each day. The nonreinforced sessions were included to reduce the possible influence of contextual cues on the development of conditioned analgesia to the discrete CS (which had been observed in earlier pilot work).

The animals were placed in the restrainer tubes, transported, and then prepared for each conditioning session as in restrainer training sessions. Beginning 10 min later, all animals received a series of four experimental-context tailflick test trials spaced 2 min apart. The first of three forward CS-US pairings was presented 2 min after the last of the experimental-context tailflick test trials. The CS consisted of a 75-sec illumination of the 28-V lamp. The US consisted of a 25-sec, 1-mA shock. US onset preceded CS offset by 1 sec. During the first CS presentation all animals received one tailflick test trial, which served as a daily test trial for conditioning to the light $\mathrm{CS}+$. The tailflicking was taken during the first $\mathrm{CS}+$ trial because here any analgesia would be produced by the CS rather than by the shock US. Subsequent CS-US presentations were separated by variable 20 -sec (range: $10-30 \mathrm{sec}$ ) intervals. The animals remained in the chambers for a total session time each day of $25 \mathrm{~min}$, at which time they were returned to the animal colony. The alternating conditioning and nonreinforced sessions continued daily until all animals as a group exhibited maximal elevations in tailflick latencies (maximal analgesia) recorded during the $\mathrm{CS}+$ presentation tailflick test trial ( 7 days total).

\section{Results and Discussion}

\section{Conditioning}

Any comparison of the backward and control groups was precluded for the acquisition data, since the control animals were not tailflick tested during the CS presentation.

Backward group tailflick latencies recorded in the experimental context alone prior to the US-CS presentations increased to maximal values over the course of the 4 conditioning days (Figure 1A). In contrast, latencies recorded

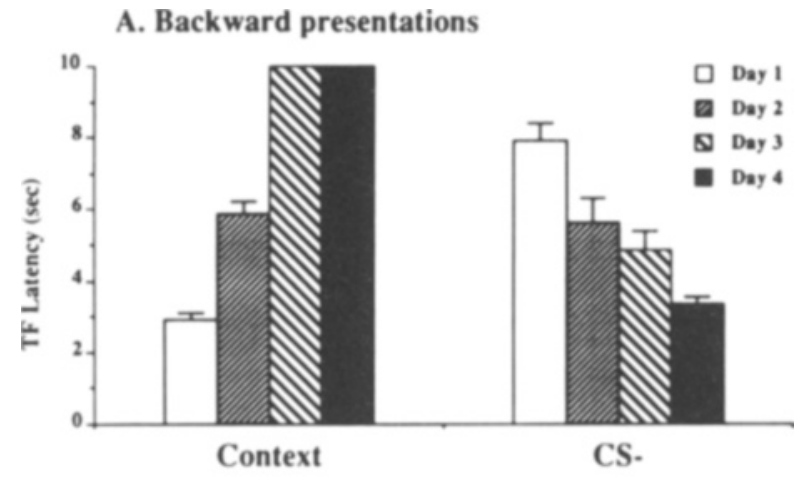

B. Control presentations

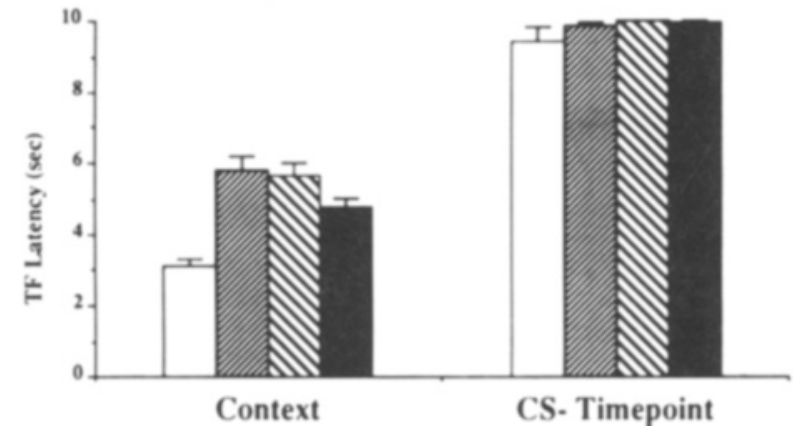

Figure 1. Acquisition of conditioned inhibition of analgesia in backward group animals in comparison with uncorrelated controks. Mean tailfick latencies recorded in the experimental context alone and during the CS- presentation (panel A, backward group) or CStimes (panel B, uncorrelated controls) are plotted. Standard error bars are included.

during the CS- presentation rapidly decreased in duration over the days of training. This pattern of increasing tailflick latencies to the context and decreasing latencies to the CS- superimposed on the context suggests the acquisition of conditioned inhibition.

A repeated measures analysis of variance (ANOVA) revealed a significant effect of the conditioning session $[F(7,49)=36.2, p<.0001]$. Post hoc Scheffé $F$ tests $(p<.05)$ further revealed that the tailflick latencies recorded during the CS- presentation on Conditioning Session Day 1 differed from those of Days 2, 3, and 4. Tailflick latencies recorded during the $\mathrm{CS}-$ presentation on Days 2, 3, and 4 did not differ from each other. Latencies recorded in the experimental context alone on Days 1 and 2 each differed from those on Days 3 and 4, while contextual latencies on Days 3 and 4 did not differ from each other, because on both days maximal analgesia was observed in response to the context alone. Except on Day 2, each tailflick latency recorded during the CS- presentation differed from its own day's experimental context latency, and each successive day's CS - tailflick latencies differed from all previous days' contextual latencies.

The control group latencies recorded during the conditioning procedure (Figure 1B) produced a very different 


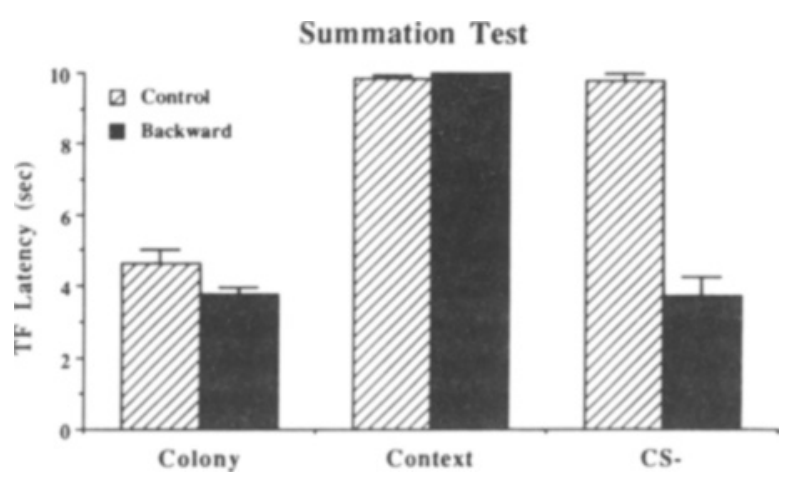

Figure 2. Summation test of conditioned inhibition for the CSemployed in the backward conditioning paradigm.

pattern. As expected in such control groups, contextual latencies increased in duration, presumably as a result of the conditioning of analgesia to the context. The latencies recorded during the time at which the CS-occurred for the backward group were asymptotic. This is presumably because the response here was to the shock US as well as the excitatory context.

\section{Summation Test}

Figure 2 shows the results of the summation testing procedure. Both groups exhibited maximal analgesia in response to the experimental context, and neither group exhibited analgesia in response to the neutral colony room context. However, the backward and control groups differed from each other in tailflick latencies recorded during the CS-. The control group continued to exhibit maximal analgesia, and the backward group yielded baseline latencies.

A 2 (groups) $\times 3$ (condition: latencies recorded during presentation of the CS-, in the experimental context, and in a third, neutral context, the colony room) mixed factor ANOVA revealed a significant difference between the groups $[F(1,14)=71.6, p<.0001]$ and the conditions $[F(2,28)=204.3, p<.0001]$, and a significant group $\times$ conditions interaction $[F(2,28)=68.6, p<$ $.0001]$. Post hoc Scheffé $F$ tests $(p<.05)$ revealed that the two groups only differed from each other in latencies recorded during the $\mathrm{CS}-$, in which the control group exhibited analgesia, and the backward group did not.

\section{Extinction of Excitatory Contextual CS+}

Figure 3 shows the results of the extinction procedure. The control group showed a rapid loss of the contextually conditioned analgesia, returning to baseline pain sensitivities in fewer sessions than the backward animals. The backward group eventually returned to baseline pain sensitivity by Day 4 .

A 2 (groups) $\times 4$ (days) $\times 6$ (tailflick test trials: latencies recorded in the experimental context alone $0,2,4$, 6,8 , and $10 \mathrm{~min}$ after placement in the context) mixed factor ANOVA was performed on the results of the extinction procedure. A significant difference was revealed between the groups $[F(1,14)=101.7, p<.0001]$, and
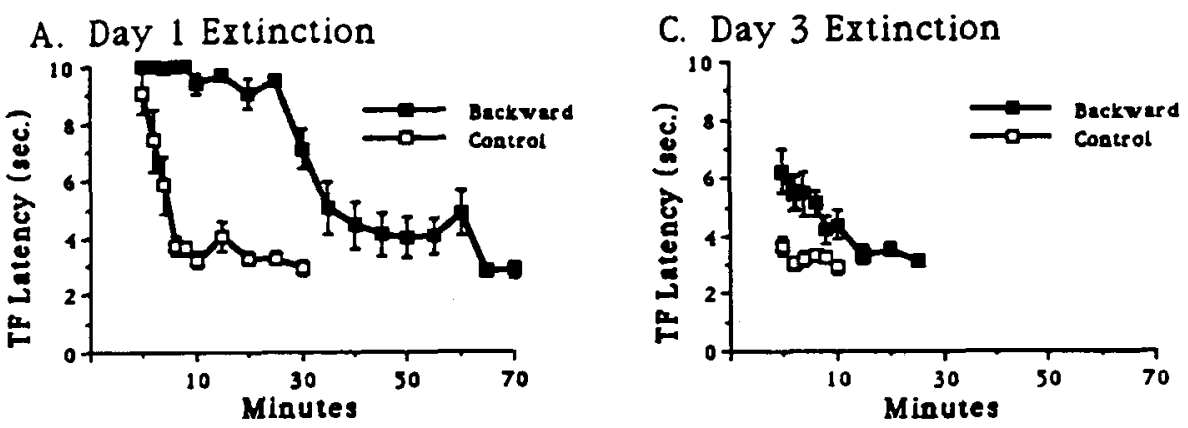

\section{B. Day 2 Extinction}

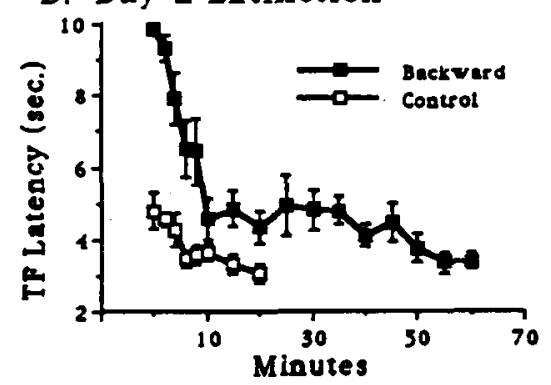

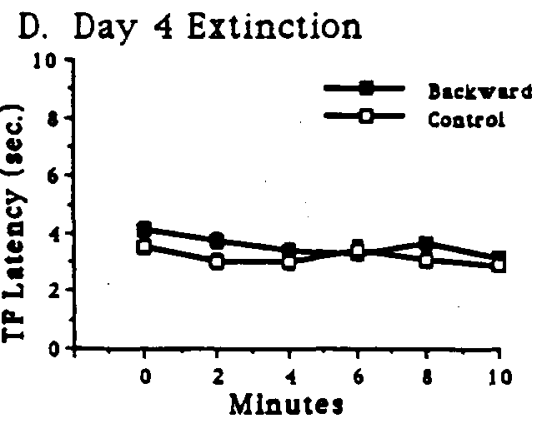

Figure 3. Extinction of contextual CS + . Mean tailfick latencies recorded in the experimental context alone (no CS- presentation) are plotted. 
for days $[F(3,42)=91.7, p<.0001]$ and test trials $[F(5,70)=36.0, p<.0001]$. The group $\times$ day interaction $[F(3,42)=19.2, p<.0001]$, the day $\times$ trials interaction $[F(15,210)=5.4, p<.0001]$, and the group $\times$ day $\times$ tailflick trials interaction $[F(15,210)=10.5$, $p<.0001]$ were significant; the group $\times$ blocked trials interaction was not significant $(p>.05)$. Post hoc Scheffe $F$ tests $(p<.05)$ revealed that the two groups differed from each other in tailflick latencies recorded at all times across days. Days 1, 2, and 3 differed between the two groups, but Day 4 did not. Reliable differences of day and tailflick trials were found for both groups.

\section{Retardation-of-Acquisition Test}

The results of the retardation-of-acquisition test are shown in Figure 4. Tailflick latencies to the CS+ presentation gradually increased in duration over the days of training, showing the acquisition of conditioned analgesia in both groups. The control group animals acquired the conditioned response more readily, exhibiting maximal analgesia to the CS+ on conditioning session Day 5, compared to Day 7 for the backward group.

A 2 (groups) $\times 7$ (days) $\times 2$ (tailflick test trials; latencies recorded in the experimental context alone, and during the CS+ presentation) mixed factor ANOVA was performed on the results of the conditioning sessions, revealing reliable effects of group $[F(1,14)=17.4, p<$ $.001]$, days $[F(6,84)=44.7, p<.0001]$, and tailflick test trials $[F(1,14)=139.3, p<.0001]$; the group $\times$ day interaction $[F(6,84)=7.3, p<.0001]$, the group $\times$ test trials interaction $[F(1,14)=26.4, p<.001]$, the day $\times$ test trials interaction $[F(6,84)=26.2, p<.0001]$, and the group $\times$ day $\times$ test trials interaction $[F(6,84)=$ $12.8, p<.0001]$ were significant. Post hoc Scheffé $F$ tests $(p<.05)$ showed that the two groups differed from each other in latencies recorded during the CS+, but not in the context alone across days. Days 1, 5, 6, and 7 differed between the two groups, but Days 2, 3,

Retardation Test:

Reinforced vs Nonreinforced Sessions

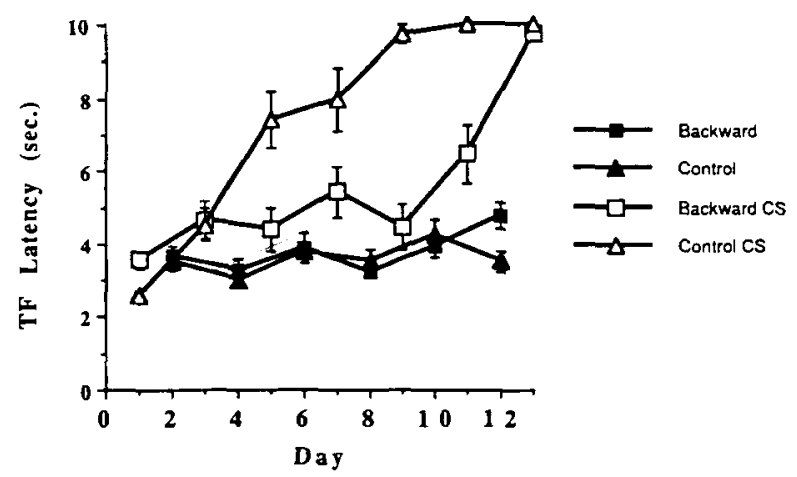

Figure 4. The retardation-of-acquisition test. For both groups, the CS- used to condition inhibition in the backward conditioning paradigm was utilized as a CS+ for conditioned analgesia (see text). and 4 did not. Reliable differences of day and tailflick tests were found for both groups.

The results of Experiment $1 \mathrm{~A}$ are consistent with the argument that stimuli paired in a backward fashion with a shock US can come to function as conditioned inhibitors of analgesia. There are, however, several difficulties that allow alternative interpretation. The amount of analgesia conditioned to the context at the end of acquisition was greater in the backward than in the control group. Even though the analgesia to the context was extinguished before retardation testing, the occurrence of shock during the retardation test might have reinstated analgesia to the context, leading to differential context controlled analgesia in the two groups. This factor could then have produced the group difference in acquisition in response to the CS. A better procedure might have been to have had two contexts, one in which shocks occurred and one in which they did not. Retardation testing could then have been conducted in the neutral context. Moreover, it could be argued that the CS in the uncorrelated control group was excitatory. Thus the difference in conditioning rate between the backward and uncorrelated groups might be interpreted as having resulted from the CS in the backward group's being neutral rather than inhibitory. The fact that the CS did not produce analgesia when first presented during retardation testing is inconsistent with this argument, but it is not decisive. Thus it would be useful to add other control conditions in which the CS is less likely to become excitatory. In Experiment 1B, we therefore examined the performance of animals trained as described above for the backward group in the retardationof-acquisition test in comparison with not only an uncorrelated control, but also $\mathrm{CS}$-alone and restraint-alone controls in a context not previously associated with the occurrence of shock.

\section{EXPERIMENT 1B}

\section{Method}

Subjects

The subjects were 32 rats as described for Experiment $1 \mathrm{~A}$ above.

\begin{abstract}
Apparatus
The apparatus was the same as that described for Experiment $1 \mathrm{~A}$ above with one modification. That is, in addition to the experimental context described in Experiment $1 \mathrm{~A}$ (here, referred to as Context A), a second training context (Context B) was employed. This second context consisted of a second room, which was connected to the shock and cue delivery sources described above. This different room was dimly illuminated and maintained at a constant $27^{\circ} \mathrm{C}$ by the same commercially available heaters. The room was equipped with ventilation fans that, together with the heaters, provided background noise. Inescapable shocks were administered while the rats were loosely restrained in the Plexiglas tubes described above. However, in this context, the floor of each of these Plexiglas tubes was modified to provide cues distinct from those available in Context $\mathrm{A}$. The entire floor of each tube was covered with a corrugated cardboard insert (Bunzl; Cincinnati, Ohio; $17.5 \times 4.5 \mathrm{~cm})$. In addition to this tactile cue, an odor cue was provided in the form of a $0.2-\mathrm{ml}$ drop of commercially obtained white vinegar placed on the cardboard at the end underlying the rats' noses.
\end{abstract}


Fresh cardboard and vinegar were used daily for each animal. Each of these Plexiglas tubes rested on individual platforms on a standard laboratory countertop at a height that allowed testing without moving the animals. Each platform was set at an approximately $40^{\circ}$ angle, so that the animal's head was elevated relative to its hindquarters. This platform angle, in addition to the corrugated cardboard and vinegar, was intended to provide the animal with salient cues distinct to this second context.

\section{Procedure}

Days 1-5: Restrainer training. The subjects first received 5 daily restrainer training sessions in each context (Context $A$, the experimentation room as described above for Experiment $1 \mathrm{~A}$, and Context B) in order to habituate them to both the restraint tubes and handling. All sessions in Context $A$ took place between 1300 and $1700 \mathrm{~h}$. All sessions in Context B took place between 0800 and $1200 \mathrm{~h}$. Thus time of day was an additional cue distinguishing the two contexts. Prior to each session, the animals were placed in the restrainer tubes while they were in the animal colony room, and then they were taken to the particular context for the session. The animals (in restrainer tubes) were placed on the platforms. Electrode paste was applied to the fuse clip electrodes, and the electrodes were attached and taped to the distal third of each animal's tail. The $28-\mathrm{V}$ lamp (unlit) was positioned $4-5 \mathrm{~cm}$ in front of the restrainer at the animal's eye level. The animals remained on the platforms in the chambers for a total session time each day of $25 \mathrm{~min}$, at which time they were returned to the animal colony. Neither shock nor light was presented during these sessions.

Days 6-9: Conditioning. On the day following the final restrainer training session, the animals were randomly assigned to the backward $(n=8)$, uncorrelated control $(n=8)$, CS-alone control $(n=$ $8)$, or restraint control $(n=8)$ group. The animals in each group were prepared for each session as described above for restrainer training, and they continued training in both contexts. In Context B, all animals received four tailflick test trials at the same times as during conditioning in Context A (see below), but no shocks or lights were presented.

In Context $\mathbf{A}$, all animals received a series of three experimentalcontext tailflick test trials spaced 2 min apart, beginning $10 \mathrm{~min}$ into the session. For the animals in the backward and uncorrelated control groups, all other procedures were as described for such groups in Experiment $1 \mathrm{~A}$ above. For the animals in the CS-alone control group, following the three tailflick test trials beginning $10 \mathrm{~min}$ into the session, all animals received three presentations of the CS (light) at the same times at which CS presentations took place for the backward group. During the third CS presentation, all animals in the CS-alone control group received one tailflick test trial. For animals in the restraint control group, all tailflick test trials took place at the same times as those for the other groups, but both US and CS presentations were omitted.

Days 10-16: Retardation-of-acquisition test. On the day following the final conditioning session, training in Context $\mathbf{A}$ was discontinued. In Context $B$, all animals received the first of what would be daily forward CS-US pairing sessions at approximately the same time each day.

The animals were placed in the restrainer tubes, transported, and then prepared for each conditioning session, as they were in restrainer training sessions. Beginning $10 \mathrm{~min}$ later, all animals received a series of three experimental-context tailflick test trials spaced 2 min apart. One forward CS-US pairing was presented 2 min after the last of the experimental-context tailflick test trials. The CS consisted of the 75-sec illumination of the 28-V lamp. The US consisted of the 25-sec, 1-mA shock. US onset preceded CS offset by $1 \mathrm{sec}$. During the CS presentation, all animals received one tailflick test trial that served as a daily test trial for conditioning to the light CS+. The tailflicking was taken during the CS+ trial because here any analgesia would be produced by the CS rather than by the shock US. The animals remained in the chambers for a total session time each day of $25 \mathrm{~min}$, at which time they were returned to the animal colony. The sessions continued daily until all animals exhibited maximal elevations in latencies (maximal analgesia) recorded during the $\mathrm{CS}+$ presentation tailflick test trial.

\section{Results and Discussion}

\section{Conditioning}

Any comparison of the four groups was precluded for the acquisition data, since the animals in two groups were not tailflick tested during the CS presentation.

As in Experiment 1A, backward group tailflick latencies recorded in the experimental context (Context A) alone prior to the US-CS presentations increased to maximal values over the course of the 4 conditioning days (Figure 5A). Latencies recorded during the CS- presentation rapidly decreased in duration over the days of training.

A repeated measures ANOVA revealed a significant effect of the conditioning session $[F(7,49)=20.9$, $p<.001]$. Post hoc Scheffé $F$ tests $(p<.05)$ further revealed that the latencies recorded during the CS- presentation on Conditioning Session Days 1 and 2 differed from those on Days 3 and 4, but not from each other. Latencies recorded during the CS- presentation on Days , 3 and 4 did not differ from each other. Latencies recorded

\section{A. Backward presentations: Daily Sessions}

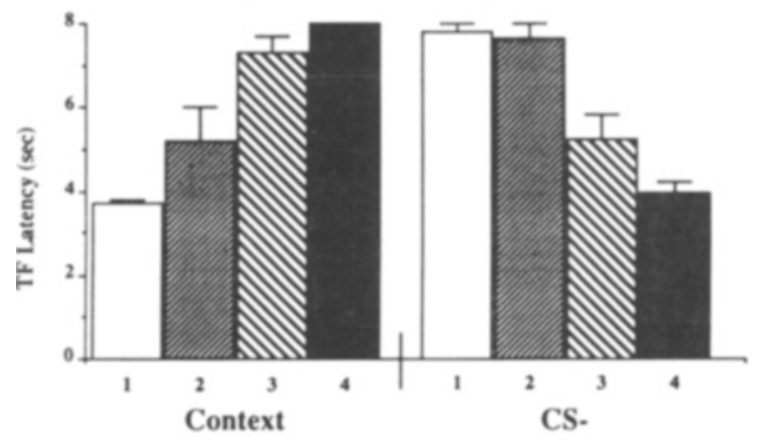

B. Control presentations: Daily Sessions

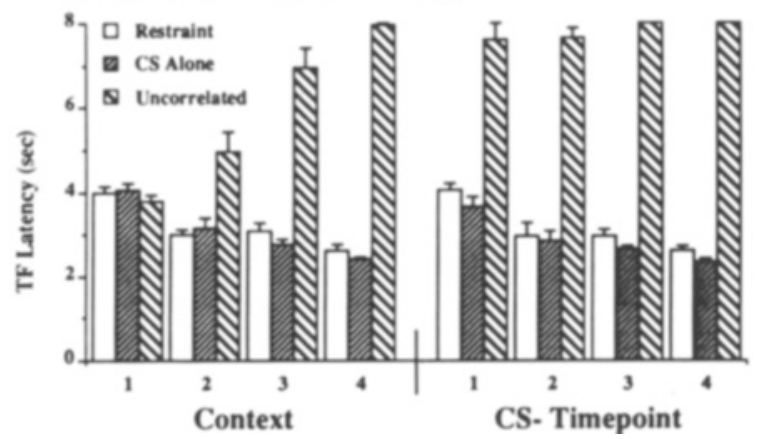

Figure 5. Context $A$ : the acquisition of conditioned inhibition of analgesia in backward group animals (panel $A$ ) in comparison with restraint, CS alone, and uncorrelated controls (panel B). Mean tailfick latencies recorded in the experimental context alone and during the CS- presentation or time (no presentation) are plotted. 


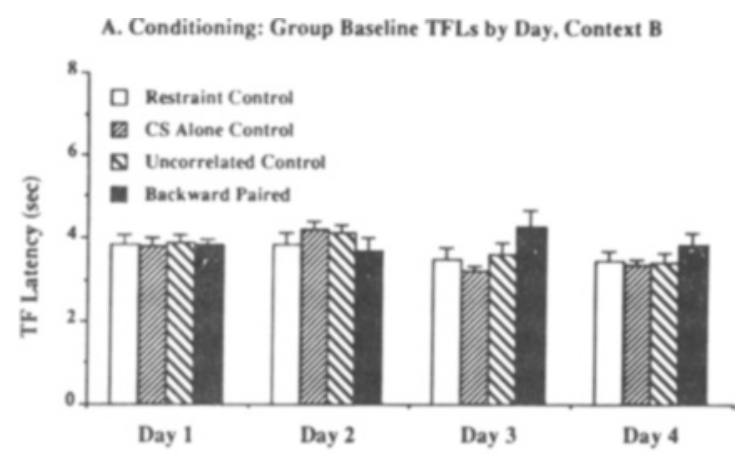

B. Conditioning: Group CS- Timepoint TFLs by Day, Context B

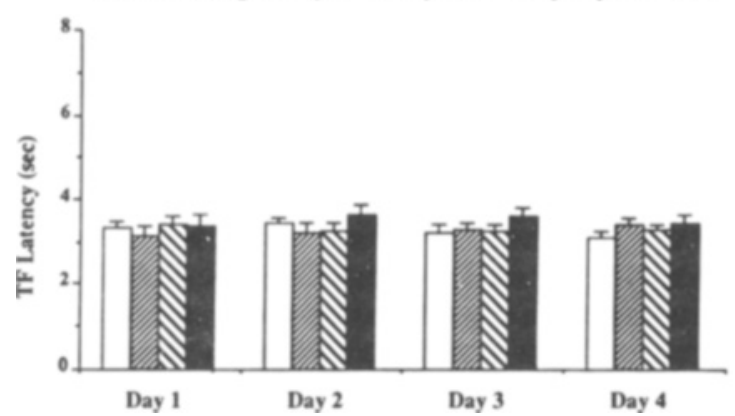

Figure 6. Context B: establishment of context neutrality for the retardation test. Mean tailfick latencies recorded in the experimenta] context alone ("Baseline TFLs") and during the CS- time (no presentation) are plotted.

in the experimental context alone on Day 1 differed from those on Days 3 and 4, as did those on Day 2 from those on Day 4, while contextual tailflick latencies on Days 3 and 4 did not differ from each other, since on both days maximal analgesia was observed in response to the context alone. With the exception of Day 2, each latency recorded during the $\mathrm{CS}-$ presentation differed from its own day's experimental context latency, and each successive day's CS-latencies differed from all previous days' contextual latencies.

The tailflick latencies to Context A during the conditioning procedure produced different patterns across the control groups (Figure 5B). For the uncorrelated control group, contextual tailflick latencies (left-hand panel) increased in duration, presumably as a result of the conditioning of analgesia to the context. As in Experiment 1A, latencies recorded during the time at which the CS-occurred for the backward group (right-hand panel) were asymptotic, again presumably because the response here was to the shock US as well as the excitatory context. For the CS-alone and restraint control groups, neither contextual nor CS- time tailflick latencies increased in duration.

In contrast to the differing response profiles observed in the four groups during the conditioning phase in Context A, latencies recorded at the same times (as occurred in Context A conditioning sessions) in Context $B$ revealed no difference between the groups in either contextual or
CS time tailflick latencies, establishing Context B as a neutral context (Figure 6).

\section{Retardation-of-Acquisition Test}

The results of the retardation-of-acquisition test are shown in Figure 7. Latencies to the CS+ presentation in Context B (bottom panel) gradually increased in duration over the days of training, showing the acquisition of conditioned analgesia in all groups. The uncorrelated, CSalone, and restraint control group animals acquired the conditioned response more rapidly than did the backward group.

A 4 (groups) $\times 7$ (days) $\times 2$ (tailflick test trials: latencies recorded in the experimental context alone, and during the $\mathrm{CS}+$ presentation) mixed factor ANOVA was performed on the results of the conditioning sessions, revealing reliable effects of group $[F(3,28)=6.0, p<$ $.01]$, days $[F(6,128)=65.9, p<.0001]$, and test trials $[F(1,28)=559.3, p<.0001]$; there were significant interactions of the group $\times$ day $[F(18,168)=2.2, p<$ $.01]$, group $\times$ test trials $[F(3,28)=13.7, p<.0001]$, day $\times$ trials $[F(6,168)=74.3, p<.0001]$, and group $\times$ day $\times$ trials $[F(18,168)=2.4, p<.01]$. Post hoc Newman-Keuls pairwise comparisons $(p<.05)$ revealed significant differences between each of the three control groups and the backward group, but not from each other.
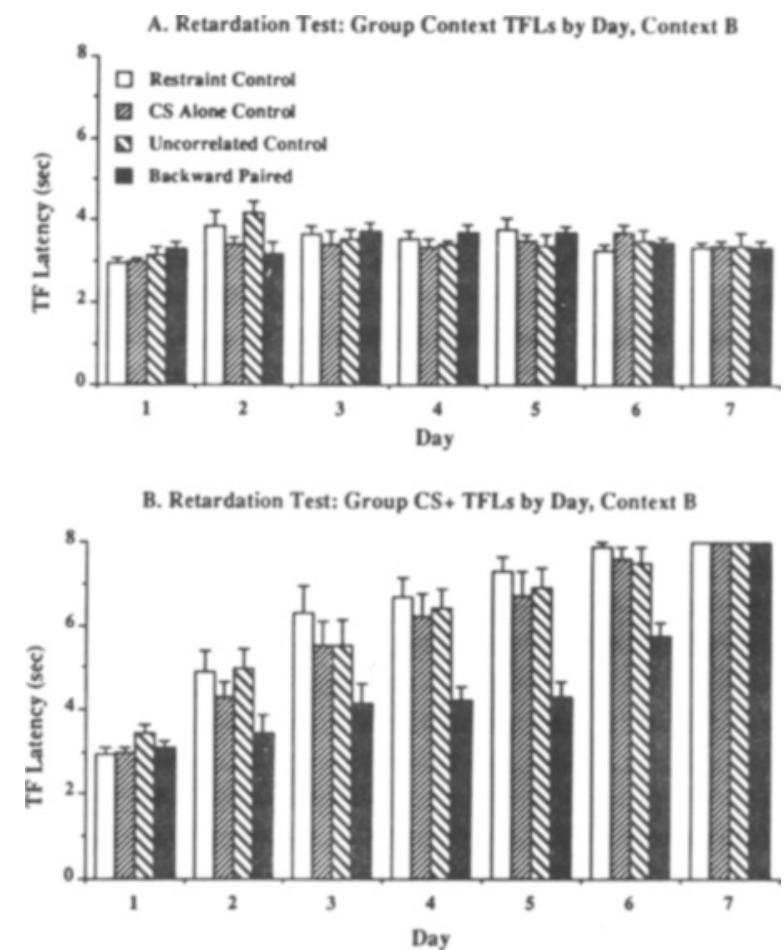

Figure 7. The retardation-of-acquisition test. For all groups, the CS- used in Context A to condition inhibition in the backward conditioning paradigm was utilized as a CS+ for conditioned analgesia in Context B. Mean tailnick latencies recorded in the experimental context alone ("Context TFLs," panel A) and during the CS+ presentation (panel B) are plotted. 
Scheffe $F$ tests $(p<.05)$ showed that the four groups differed from each other in tailflick latencies recorded during the CS+, but not in the context alone (top panel) across days. Days 2, 3, 4, 5, and 6 differed between the four groups, but Days 1 and 7 did not. Reliable differences of day and tailflick tests were found for all groups.

In sum, Experiment 1B overcame many of the difficulties of Experiment 1A. The retardation test was conducted in a context that produced no analgesia whatsoever at any point during training. The fact that conditioning to the CS was not slower in the CS-alone control than in the restraint control indicates that the differences between the two contexts were salient. This is because latent inhibition (slower conditioning to a preexposed CS) essentially does not survive a change in context (Lovibond, Preston, \& Mackintosh, 1984; Swartzentruber \& Bouton, 1986). Moreover, the use of two different contexts prevented the difference in conditioning to the shock context between backward and uncorrelated groups that was observed in Experiment $1 \mathrm{~A}$. Importantly, tailflick latencies to the first presentation of the CS during retardation testing did not differ among the groups. Finally, conditioning to the CS was slower in the backward group than in groups for which the CS cannot be argued to have gained excitatory strength during the conditioning phase. The fact that conditioning in the backward group was retarded relative to conditioning in the uncorrelated, CS-alone, and restraint control groups can only be interpreted as inhibition having been conditioned to the CS.

The results of Experiments 1A and 1B are all consistent with the conclusion that a stimulus that is presented after shock in a backward fashion comes to be a conditioned inhibitor of analgesia. However, this conclusion rests on the assumption that the tailflick to radiant heat reflects pain sensitivity/reactivity. It is possible that the increased latencies that were observed in response to the cues present during shock did not represent decreased responsiveness to painful input, but rather a general motor inhibition or general insensitivity to sensory input.

One approach to assessing these possibilities was to determine tailflick responding to a nonpainful input to the tail (Illich \& Grau, 1990). If the increased latencies that occurred in the shock context represented an analgesic response, tailflicking to nonpainful input to the tail should remain at normal levels in the presence of the shock context. Such a result would support the conclusion that the reversal of increased latencies produced by the CS- for shock represents conditioned inhibition of analgesia. For this reason, Von Frey hairs (Kenshalo, 1972) were used to provide nonpainful input to the tail. Although there is good reason to believe that the tactile stimulation provided by Von Frey hairs is not painful (Kenshalo, 1972), further experimental validation would be useful. Morphine is known to inhibit responding to painful but not to nonpainful sensory stimulation (Gilman, Goodman, \& Gilman, 1980). Thus, in Experiment 2A, we explored the effect of morphine on tailflicking to radiant heat and stimulation by Von Frey hairs.

\section{EXPERIMENT 2A}

\section{Method}

Subjects

The subjects were 10 experimentally naive rats like those in Experiment 1 .

\section{Apparatus}

The apparatus was the same as that described for Context $B$ in Experiment 1B, with the omission of the cardboard, vinegar, and platform angle cues. Animals (in tubes) were transported to the experimentation room and placed on elevated, level platforms, the height of which allowed for testing. In addition, calibrated Von Frey hairs were employed to determine their usefulness as nonpainful input to the tail. The Von Frey hairs were constructed by affixing one end of an approximately 2 -cm-long section of horse hair across the width of 15-cm-long wooden applicators (Puritan; Guilford, ME) with epoxy. The individual hairs were calibrated by pressing the free end of the hair to the surface of the weighing dish of a standard digital laboratory scale. The pressure in grams necessary to bend the hair was then modified by trimming the hair with scissors until the requisite value was obtained.

\section{Procedure}

All animals received 5 daily restrainer training sessions in order to habituate them to handling and to the tubes. On the day following the final restrainer training session, all of the animals were randomly divided into two drug groups: $2-\mathrm{mg} / \mathrm{kg}$ s.c. morphine or saline control. The animals were tested for responsivity to both nociceptive stimulation (tailflicking) and tactile pressure using 7.0-g calibrated Von Frey hairs. Pilot testing had shown that $7.0 \mathrm{~g}$ of pressure would induce tailflick latencies of 2-3 sec with low variability when the hair was applied to the tail. Both tests used the animal's latency to "flick" the tail away from the locus of stimulation as the dependent measure. For Von Frey hair testing, the tip of the hair was touched (manually, using the wooden applicator) to the dorsal surface of the tail, and downward pressure was then applied to the point of bending the hair. The latency from the onset of downward pressure with the hair until the tail "flicked" was measured with a standard stopwatch.

The subjects were weighed (to determine drug dosage) and then placed in the restrainer tubes in the same fashion as described above. Ten minutes after placement in the experimentation room, the animals received alternating radiant heat (tailflicking) and Von Frey hair test trials spaced $1 \mathrm{~min}$ apart to establish baseline radiant heat and Von Frey hair tailflick latencies. For half of the animals in each group, radiant heat testing occurred first, and for the other half Von Frey hair testing occurred first. The test trials continued until latencies for each measure in each animal stabilized to a range of $0.5 \mathrm{sec}$ across three test trials. The animals were then injected with either morphine $(2 \mathrm{mg} / \mathrm{ml} / \mathrm{kg})$ or saline $(1 \mathrm{ml} / \mathrm{kg})$, according to group assignment. All animals were tested for radiant heat and Von Frey tailflick responding at $10,20,30,40,50$, and 60 min postinjection, at which time they were returned to the colony room.

\section{Results and Discussion}

As can be seen in Figure 8, the inhibition of tailflicking produced by morphine was specific to radiant heat stimulation. Tailflicks recorded with the Von Frey hairs did not vary across the drug conditions, whereas tailflicks recorded to radiant heat did.

A 2 (group: morphine or saline) $\times 2$ (measure: radiant heat or Von Frey tailflick) $\times 2$ (test condition: predrug or postdrug mean tailflick latencies) mixed factor ANOVA revealed reliable effects of group $[F(1,8)=10.5, p<$ 


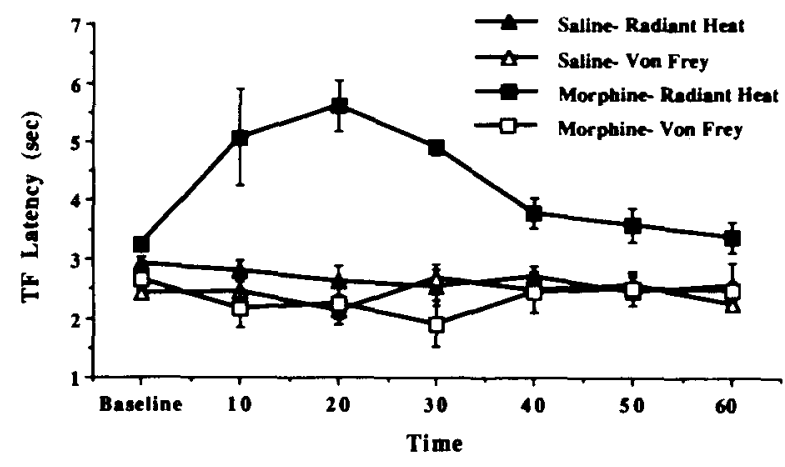

Figure 8. Effects of morphine ( $2 \mathrm{mg} / \mathrm{kg}$, s.c.) or equivolume saline on painful thermal (radiant heat) versus nonpainful tactile (Von Frey hair) stimulation of the tail.

$.05]$ and measure $[F(1,8)=88.4, p<.0001]$, as well as reliable interactions of group $\times$ measure $[F(1,8)=$ $39.7, p<.001]$, group $\times$ test condition $[F(1,8)=9.8$, $p<.05]$, measure $\times$ test condition $[F(1,8)=12.3, p<$ $.01]$, and group $\times$ measure $\times$ test condition $[F(1,8)=$ $20.0, p<.01]$. The effect of test condition $[F(1,8)=$ $1.4, p>.05$ ] was not reliable. Post hoc Scheffé $F$ tests $(p<.05)$ revealed that $(1)$ significant differences existed between the groups for radiant heat but not for the Von Frey tailflicks; (2) significant differences existed between radiant heat and Von Frey tailflicks for animals given morphine, but not for animals given saline; (3) significant differences existed between the groups for postdrug but not for predrug latencies, with predrug latencies significantly different from postdrug latencies only in animals given morphine; and (4) while significant differences existed between the measures (radiant heat or Von Frey) at both pre- and postdrug testing, pre- and postdrug testing were significantly different only for radiant heat testing, and not for Von Frey testing.

The systemic (s.c.) administration of morphine affected only tailflick latencies obtained with the use of the radiant heat tailflick apparatus. These results substantiate the argument that the latencies obtained with the use of Von Frey hairs reflect the effects of nonpainful stimulation of the tail. Furthermore, these results support the argument that the tailflick changes observed with the use of radiant heat reflect effects specific to the modulation of nociceptive information. Therefore, in Experiment 2B, radiant heat and Von Frey hair stimulation were employed as painful and nonpainful sensory inputs to the tail. This allowed for examination of the possibility that the increased latencies that were observed in response to the cues present during shock in Experiment 1 represented decreased responsiveness to painful input.

\section{EXPERIMENT 2B}

\section{Method}

Subjects

The subjects were 18 experimentally naive rats as described above.

\section{Apparatus}

The apparatus was the same as that described in Experiment $2 \mathrm{~A}$

\section{Procedure}

Following the completion of restrainer training, the condition ing initially proceeded as described for backward conditioning in Experiment 1 above. Daily conditioning sessions were continued for 3 days, at which time all animals exhibited conditioned inhibition of analgesia in response to the $\mathrm{CS}-$. On the day of Conditioning Session 4, in a counterbalanced, within-subject design, all animals were tested for responsivity to both nociceptive stimulation (tailflicking) and tactile pressure using 7.0-g calibrated Von Frey hairs. Tests of both types of stimulation were conducted in the colony room, in the experimental context, and during the $\mathrm{CS}-$ presentation.

The subjects were placed in the restrainer tubes in the same fashion as described in Experiment 1 above. Ten minutes later, the animals received eight alternating radiant heat and $V_{\text {on }}$ Frey hair test trials (four each) spaced $1 \mathrm{~min}$ apart while they were in the colony room, to establish nonexperimental context baseline radiant heat and Von Frey hair tailflick latencies. For half of the animals, radiant heat testing occurred first, and for the other half, Von Frey hair testing occurred first. The animals were then taken to the experimentation room and prepared for the session as usual for backward conditioning. At $10 \mathrm{~min}$ into the session, all animals received eight counterbalanced, alternating radiant heat and Von Frey hair test trials (four each) spaced 1 min apart. Two minutes after the final test trial, the first of three US-CS pairings was presented, in the same manner as in all backward conditioning sessions. During the third CS presentation, all animals received both radiant heat and Von Frey hair test trials in counterbalanced order (one each). The animals remained in the experimental context for a total session time of $25 \mathrm{~min}$, at which time they were retumed to the colony room.

\section{Results and Discussion}

As can be seen in Figure 9, the inhibition of tailflicking produced by contextual cues that had been paired with shock was specific to nociceptive stimulation. Tailflicks recorded with the Von Frey hairs did not vary across the three conditions, whereas tailflicks to radiant heat did.

A 2 (measure: tailflicks or Von Frey) $\times 3$ (test condition: colony room, experimental context, $\mathrm{CS}-$ presentation) ANOVA revealed reliable effects of the measure $[F(1,17)=388.2, p<.0001]$ and test condition $[F(2,34)$ $=110.2, p<.0001]$, as well as a reliable measure $\times$

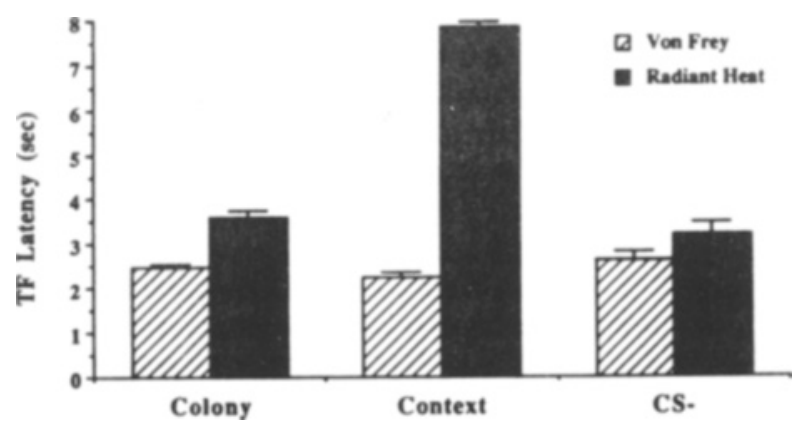

Figure 9. Specificity of conditioned inhibition in the backward conditioning paradigm in response to painful stimuli. Both thermal heat and Von Frey hair taillick latencies were recorded during the CSpresentation, in the experimental context alone, and in a third neutral context (colony room). 
test condition interaction $[F(2,34)=193.8, p<.0001]$. Post hoc Scheffé $F$ tests $(p<.05)$ revealed that while significant differences existed in the three test conditions for the tailflick apparatus, such was not the case for the Von Frey hairs. These results substantiate the argument that the tailflick changes observed in Experiment 1 tailflick latencies reflect effects specific to the modulation of nociceptive information.

\section{GENERAL DISCUSSION}

The results of Experiments 1A and IB establish the effectiveness of this backward-conditioning paradigm for establishing the conditioned inhibition of analgesia. The presentation of the CS- produced an abrupt change in pain sensitivity, essentially "switching off" conditioned analgesia. The results of the summation and retardation-ofacquisition tests in Experiment $1 \mathrm{~A}$ were consistent with the conclusion that the stimulus that had been paired with shock in a backward fashion became a conditioned inhibitor of analgesia. The results of Experiment $1 B$ replicate the findings of Experiment 1A. The differential results of the retardation test for the four groups of Experiment 1B provide strong support for the conclusion that the CS- came to function as a conditioned inhibitor. The results of Experiments $2 \mathrm{~A}$ and $2 \mathrm{~B}$ support the argument that the tailflick latency changes observed in Experiment 1 reflect effects specific to the modulation of nociceptive information.

The demonstration that stimuli paired with shock in a backward fashion become conditioned inhibitors of analgesia does not implicate a particular mechanism by which the inhibition occurs. There are a number of different reasons why the backward stimulus might have inhibited the analgesic reaction. These different possibilities derive from the several different mechanisms that might be responsible for the excitatory conditioning of analgesia. Three hypotheses have been proposed. (1) The analgesic CR is directly conditioned. Here the analgesic response that is produced by the US (see Maier, 1989, 1990 ) is directly conditioned to the CS (Watkins, Kinscheck, \& Mayer, 1983). (2) The analgesic response is not directly conditioned to the CS. Fear is conditioned to the CS, and the analgesic response to the CS is a reaction to the fear (Fanselow, 1986). (3) The analgesic response is not directly conditioned to the CS. The CS acquires the ability to evoke an active mental representation of the US, and the analgesia is a reaction to this representation's being active (Grau, 1987).

Thus it is possible to argue that the CS- inhibited the analgesia because it directly inhibited the analgesia response system. Here the notion might be that the CScame to activate a pathway that descends to the spinal cord, where it inhibits the machinery that produces decreases in ascending pain transmission (Baber, Dourish, \& Hill, 1989; Suberg \& Watkins, 1987; Watkins, Kinscheck, \& Mayer, 1985). Thus the CS- would lead to an inhibition at the efferent end of the analgesia pathway. However, it is also possible that the CS - inhibited analgesia in the present studies by acting on fear or the representation of shock. This is quite different from an action at the efferent parts of the pathway that directly affect pain processing. Obviously, these are not mutually exclusive and more than one may be correct.

\section{REFERENCES}

AKIL, H., \& MAYER, D. J. (1972). Antagonism of stimulation produced analgesia by p-CPA, a serotonin synthesis inhibitor. Brain Research, 44, 692-697.

BaBER, N. S., Dourish, C. T., \& HILl, D. R. (1989). The role of CCK, caerulein, and CCK antagonists in nociception. Pain, 39, 307-328.

Basbaum, A. I., Fields, H. L. (1984). Endogenous pain control systems: Brainstem spinal pathways and endorphin circuitry. Annual Review of Neuroscience, 7, 309-338.

D'Amour, F. E., \& Sith, D. L. (1941). A method for determining loss of pain sensation. Journal of Pharmacological \& Experimental Therapies, 72, 74-79.

FANSELOW, M. S. (1986). Conditioned fear-induced opiate analgesia A competing motivational state theory of stress analgesia. In D. D. Kelly (Ed.), Stress-induced analgesia (Annals of the New York Academy of Sciences, Vol. 467, pp. 40-54). New York: New York Academy of Sciences.

Gilman, A. G., Goodman, L. S., \& Gilman, A. (1980). Goodman and Gilman's The pharmacological basis of therapeutics (6th ed.). New York: Macmillan.

GraU, J. W. (1987). The central representation of an aversive event maintains the opioid and nonopioid forms of analgesia. Behavioral Neuroscience, 101, 272-288.

Grumbach, L. (1966). The prediction of analgesic activity in man by animal testing. In R. S. Knighton \& P. R. Dunke (Eds.), Pain (pp. 163-182). Boston: Little, Brown.

ILlich, P. A., \& Grau, J. W. (1990). The impact of shock on reactivity to a tactile stimulus. Learning \& Motivation, 21, 287-299.

Kenshalo, D. R. (1972). The cutaneous senses. In J. W. Kling \& L. A. Riggs (Eds.), Woodworth \& Schlosberg's Experimental psychology: Vol. 1. Sensation and perception (pp. 117-166). New York: Holt, Rinehart \& Winston.

Lovibond, P. F., Preston, G. C., \& Mackintosh, N. J. (1984). Context specificity of conditioning, extinction, and latent inhibition. Journal of Experimental Psychology: Animal Behavior Processes, 10, 360-375.

MAIER, S. F. (1989). Determinants of the nature of environmentally induced hypoalgesia. Behavioral Neuroscience, 103, 131-143.

MAIER, S. F. (1990). Diazepam modulation of stress-induced analgesia depends on the type of analgesia. Behavioral Neuroscience, 104, 337-345.

Moscovitch, A., \& LoLordo, V. M. (1968). Role of safety in the Pavlovian backward fear conditioning procedure. Journal of Comparative \& Physiological Psychology, 66, 673-678.

Pavlov, I. P. (1927). Conditioned reflexes. Oxford: Oxford University Press.

Rescorla, R. A. (1969). Conditioned inhibition of fear resulting from negative CS-US contingencies. Journal of Comparative \& Physiological Psychology, 67, 504-509.

SUBERG, S. N., \& W ATKINS, L. R. (1987). Interaction of cholecystokinin and opioids in pain modulation. In H. Akil \& J. W. Lewis (Eds.), Neurotransmitters and pain control (pp. 247-265). Basel: Karger.

SWartzentruber, D. . Bouton, M. E. (1986). Contextual control of negative transfer produced by prior CS-US pairings. Learning \& Motivation, 17, 366-385.

Watkins, L. R., Cobelli, D. A., \& MaYer, D. J. (1982). Classical conditioning of front paw and hind paw footshock induced analgesia (FSIA): Naloxone reversibility and descending pathways. Brain $R e-$ search, 243, 119-132. 
Watkins, L. R., Kinscheck, I. B., \& MAYER, D. J. (1983). The neural basis of footshock analgesia: The effect of periaqueductal gray lesions and decerebration. Brain Research, 276, 317-324.

Watkins, L. R., Kinscheck, I. B., \& MAyer, D. J. (1984). Potentiation of opiate analgesia and apparent reversal of morphine tolerance by proglumide. Science, 224, 395-396.

Watkins, L. R., Kinscheck, I. B., MAyer, D. J. (1985). Potentiation of morphine analgesia by the CCK antagonist proglumide. Science, 327, 169-180.
Willams, D. A., \& Overmier, J. B. (1988). Backward inhibitory conditioning with signaled and unsignaled unconditioned stimuli: Distribution of trials across days and intertrial interval. Joumal of Experimental Psychology: Animal Behavior Processes, 14, 26-35.

(Manuscript received August 15, 1991; revision accepted for publication February 28, 1992.) 